\title{
Mono-institutional retrospective cohort analysis of the insurance status dependent access to ENT-professionals and survival in head and neck squamous cell carcinoma
}

\author{
Andreas Knopf ${ }^{1,2^{*}}$ D, Simon Teutsch ${ }^{2}$ and Henning Bier ${ }^{2}$
}

\begin{abstract}
Background: To access the influence of insurance status on time of diagnosis, quality of treatment and survival in head and neck squamous cell carcinoma (HNSCC).

Methods: This mono-institutional retrospective cohort analysis included all HNSCC patients $(n=1,054)$ treated between 2001 and 2011, and subdivided the cohort according to the insurance status. Differences between the groups were analyzed using the Chi square and the unpaired student's t-test. Survival rates were calculated by Kaplan-Meier and Cox regression for forward selection.

Results: Nine hundred twenty-five patients showed general, 129 private insurance. The 2 groups were equal regarding age, gender, tumor localization, therapy, and N/M/G/R-status. The T-status differed significantly between the groups showing more advanced tumors in patients with general insurance $(p=0.002)$. While recurrence-free survival was comparable in both groups, overall survival was significantly better in private patients $(p=0.009)$. The time frame between first symptom and diagnosis was equal in both groups.

Conclusions: The time frame between subjective percipience of first symptom and final therapy did not differ between the groups. In our cohort, access to otorhinolaryngological specialists is favorable in both, patients with general and private insurance. Recurrence-free survival was comparable in both groups, indicating successful HNSC $\mathrm{C}$ treatment both groups. However, overall survival was significantly better in patients with private insurance suggesting other socioeconomic factors influencing survival.
\end{abstract}

Keywords: Insurance status, outcome, survival, Head and neck squamous cell carcinoma, Socioeconomic status

* Correspondence: knopf.ent@gmail.com

'Henning Bier died before manuscript submission.

'Otorhinolaryngology/Head and Neck Surgery, Faculty of Medicine,

University of Freiburg, Killianstr. 5, 79106 Freiburg, Germany

${ }^{2}$ Otorhinolaryngology/Head and Neck Surgery, Ismaninger Str. 22, 81675

München, Germany

(c) The Author(s). 2021 Open Access This article is licensed under a Creative Commons Attribution 4.0 International License, which permits use, sharing, adaptation, distribution and reproduction in any medium or format, as long as you give appropriate credit to the original author(s) and the source, provide a link to the Creative Commons licence, and indicate if changes were made. The images or other third party material in this article are included in the article's Creative Commons licence, unless indicated otherwise in a credit line to the material. If material is not included in the article's Creative Commons licence and your intended use is not permitted by statutory regulation or exceeds the permitted use, you will need to obtain permission directly from the copyright holder. To view a copy of this licence, visit http://creativecommons.org/licenses/by/4.0/ The Creative Commons Public Domain Dedication waiver (http://creativecommons.org/publicdomain/zero/1.0/) applies to the data made available in this article, unless otherwise stated in a credit line to the data. 


\section{Background}

In the past decades, many therapeutic efforts were made to improve the prognosis of head and neck squamous cell carcinoma (HNSCC) patients. However, according to surveys of the Robert-Koch-Institute, the overall five-year survival in Germany is less than 50\% [1]. Variables like age, gender, tumour location, and histological grading are known independent prognostic parameters. One main factor influencing patients' survival is the insurance status. Many studies analyse mortality and disease-modifying parameters related to specific country-related healthcare systems. Particularly, in countries without compulsory insurance, uninsured patients show advanced tumour stages at the time of diagnosis, hence poor survival [2-5]. Other countries such as Japan did not observe differences in survival parameters with the insurance status [6]. In Germany, there is a long history of compulsory insurance attributed to Bismarck's governmental decision in 1883. However, different access to the healthcare system concerning general or private insurance status, and therefore prolonged diagnosis and treatment in patients with general insurance, is still a debate. While tumour stage at diagnosis is an important prognostic factor for HNSCC patients $[7,8]$, the correlation between the time from diagnosis to treatment (TTI) and overall survival has been statistically proven, indicating that early treatment leads to better survival. More recently, TTI longer than 40-50 days showed a significantly worse outcome $[9,10]$. However, data exploring the interval between the first symptom and cancer diagnosis (TTD) are still lacking. The perception of the first symptoms is affected by many subjective factors. In a prospective study, Dekate et al. tried to identify parameters that lead to late diagnosis in HNSCC [11]. The location of the tumour had a high impact, with hypopharyngeal cancer being one of the last to show clinical symptoms. Other factors delaying the time to diagnosis were advanced age and male gender, while easy access and early presentation to a specialist significantly reduced time to diagnosis. Early cancer diagnosis, therefore, depends on one hand, on the time till patients consult specialists after noticing the first symptom (patients delay), and on the other hand, on the prompt action of the physician (professional delay). Shafer et al. showed an avoidable delayed diagnosis in $15 \%$ of HNSCC patients which was caused likewise by the patient and the doctor [12-14]. However, reasons for patients' delay and especially the influence of socioeconomic factors on delayed diagnosis represent an underestimated and still insufficiently researched risk factor in the survival of HNSCC.

The current study analyses the insurance status as a risk factor for delayed access to ENT-professionals, delaying cancer diagnosis and therefore, reduced recurrence-free and overall survival.

\section{Methods}

Between January 2001 and December 2011, all patients who were treated for HNSCC were included in a monoinstitutional retrospective cohort study. Data collection was done by a hospital-based data-acquisition system $\left(\mathrm{SAP}^{\circ}\right)$ and validated for all patients by the regional tumour registry. Follow-up of survival parameters was done for at least 5 years in all patients, last updated in 2018. Histological samples were analysed by at least 2 experienced pathologists. Carcinoma in situ and other histological subtypes were excluded. Disease-related data such as age at diagnosis, sex, tumour location, TNMstatus (UICC 7th edition), treatment modalities, and resection status were retrospectively collected. The period from the first symptoms until diagnosis was estimated in weeks. Patients were divided into 2 groups: patients with general (1) and private (2) insurance. Overall and recurrence-free survivals were analysed for all patients. Patients with lacking data, incomplete staging, and refused/incomplete treatment were excluded from survival analysis. Differences between the two groups were analysed using the Chi-squared test. Fisher's exact test and the unpaired student's t-test were used for categorical and continuous variables, respectively. Survival rates and curves were calculated and illustrated by the KaplanMeier method and further analysed by the log-rank test. Parameters with potential impact on survival were analysed with Cox regression for further selection. Pvalues $<0.05$ were considered statistically significant. Statistical analysis was done using SPSS (SPSS Inc., Chicago, IL).

\section{Ethical considerations}

Clinical data were collected retrospectively from the daily ENT routine. Patient data were analysed pseudonymised and published anonymised. The study was approved by the local Ethics Commission, Technical University Munich (No. 104/18S).

\section{Results \\ Epidemiology of the HNSCC cohort}

A total of 1,054 patients with HNSCC were included in our study with 925 and 123 patients having general and private insurances, respectively. Subgroup analysis of insurance status did not show differences in age and gender distribution $(p=0.06 ; p=0.19$; Table 1$)$. The mean age at diagnosis was 60 and 62 years with a striking predominance for male patients (79\%, 84\%; Table 1). In both groups, oropharyngeal HNSCC (39\%; 40\%) represented the most frequent tumour site, followed by hypopharyngeal $(21 \%, 21 \%)$, laryngeal $(20 \% ; 21 \%)$, and oral (15\%; 11\%) cancers (Table 1). Nasopharyngeal and sinonasal cancers, as well as cancer of unknown primary (CUP), accounted for $<5 \%$ in each subgroup. There were 
Table 1 Epidemiologic data of a typical HNSCC cohort, subdivided due to the insurance status. CUP: Cancer of unknown primary; C-/RT: Chemo-radiation

\begin{tabular}{|c|c|c|c|}
\hline & General insurance & Private insurance & $p$-value \\
\hline$n$ & 925 & 129 & \\
\hline Age (years) & & & 0.06 \\
\hline Median & 60 & 62 & \\
\hline Mean \pm SD & $60 \pm 10$ & $62 \pm 11$ & \\
\hline Sex, n (\%) & & & 0.19 \\
\hline Male & 731 (79) & $108(84)$ & \\
\hline Female & $194(21)$ & $21(16)$ & \\
\hline Location, n (\%) & & & 0.52 \\
\hline Sinonasal & $32(4)$ & $3(2)$ & \\
\hline Nasopharynx & $14(2)$ & $5(4)$ & \\
\hline Oropharynx & $363(39)$ & $52(40)$ & \\
\hline Hypopharynx & $192(21)$ & $27(21)$ & \\
\hline Larynx & $180(20)$ & $27(21)$ & \\
\hline Oral cavity & $140(15)$ & $14(11)$ & \\
\hline CUP & $4(<1)$ & $1(1)$ & \\
\hline T stage, n (\%) & & & 0.002 \\
\hline $\mathrm{T} 1 / 2$ & $503(54)$ & $87(67)$ & \\
\hline $\mathrm{T} 3 / 4$ & $418(45)$ & $41(32)$ & \\
\hline N stage, n (\%) & & & 0.86 \\
\hline NO & $366(40)$ & $50(39)$ & \\
\hline $\mathrm{N}+$ & $559(60)$ & $79(61)$ & \\
\hline M stage, n (\%) & & & 0.76 \\
\hline MO & $886(96)$ & $127(98)$ & \\
\hline M1 & $39(4)$ & $2(2)$ & \\
\hline Grading, n (\%) & & & 0.20 \\
\hline G1 & $39(4)$ & $5(4)$ & \\
\hline G2 & $452(49)$ & $53(41)$ & \\
\hline G3 & $407(44)$ & $62(48)$ & \\
\hline G4 & $27(3)$ & $5(7)$ & \\
\hline R status, n (\%) & & & 0.24 \\
\hline Ro & $510(83)$ & $78(80)$ & \\
\hline R1 & $52(9)$ & $6(6)$ & \\
\hline R2 & $11(2)$ & $3(3)$ & \\
\hline Rx & $40(7)$ & $10(10)$ & \\
\hline UICC stage, n (\%) & & & 0.14 \\
\hline UICC I & $136(15)$ & $21(16)$ & \\
\hline UICC II & $117(13)$ & $17(13)$ & \\
\hline UICC III & $152(16)$ & $26(20)$ & \\
\hline UICC IV & $513(56)$ & $63(49)$ & \\
\hline Therapy, n (\%) & & & 0.31 \\
\hline Surgery & $164(18)$ & $23(18)$ & \\
\hline Surgery + C/RT & $433(47)$ & $69(54)$ & \\
\hline $\mathrm{pC} / \mathrm{RT}$ & $328(35)$ & $37(29)$ & \\
\hline
\end{tabular}


significant differences in the $\mathrm{T}$ status. While 418 patients (45\%) with general insurance showed T3/4 status, 41 patients (32\%) with private insurance had an advanced $\mathrm{T}$ status (32\%) ( $p=0.002$; Table 1$)$. Lymph node positivity was demonstrated in $60 \%$ and $61 \%$ of the underlying subgroup ( $p=0.86$; Table). The vast majority of patients (96-98\%) had no distant metastasis at the time of diagnosis $(p=0.76$; Table 1$)$. A high percentage of regional lymph node metastasis in both groups with a UICC stage 4 disease in 513 (56\%) and $63(49 \%)$ patients with general and private insurances, respectively $(p=0.14$; Table 1). In both groups, $18 \%$ of patients underwent primary surgery without adjuvant treatment. Surgery with adjuvant chemo-/radiation was applied in 433 (47\%) and $69(54 \%)$ patients with general and private insurances, respectively. Primary chemo-/radiation was recommended in 328 (35\%) patients with general insurance and 37 patients $(29 \%)$ with private insurance $(p=0.31$; Table 1).

\section{Insurance status and survival in HNSCC}

The time between the first symptom and final therapy was hypothesised to influence survival in HNSCC. The entire cohort was stratified into 3 groups according to the time frame of the first symptom to final therapy $(<8$ weeks, 8-12 weeks and $>12$ weeks). In patients with a time frame $<8$ weeks, the mean time between the first symptom and final therapy was $4.1 \pm 1.6$ weeks (median: 4 weeks), $9.9 \pm 1.8$ weeks (median: 10 weeks) in the group of 8-12 weeks, and $27.0 \pm 12.3$ weeks (median: 25 weeks) in patients with time frame $>12$ weeks. Survival analysis did not reveal differences between the analysed groups (Fig. 1). Analysis of mean and median time from first symptom to final therapy showed no differences between patients with general and private insurance $(p=$ $0.23)$. The mean time in patients with general insurance was $12.0 \pm 11$ weeks (median: 8 weeks) and 13.0 \pm 13 weeks (median: 8 weeks) in those with private insurance. Subgroup analysis of overall survival due to different insurance status showed significant differences between the groups. While patients with general insurance showed a median overall survival of 50 months [95\% CI: 36-64], patients with private insurance showed a significantly better median overall survival of 84 months [95\% CI: 66-102] ( $p=0.009$; Fig. 2). Cox regression for further selection, analysing symptom duration, $\mathrm{T}$-, and $\mathrm{N}$-status, identified both, advanced T (T1/2 vs. T3/4; $p<0.0001$; HR: 2.2 ) and $\mathrm{N}(\mathrm{N} 0$ vs. $\mathrm{N}+; p<0.0001 ; \mathrm{HR}: 1.9)$ status being disease-modifying parameters (Table 2). Interestingly, there was no difference in the recurrence-free survival between the groups ( $p=0.88$; Fig. 2$)$.

\section{Discussion}

While many studies aim to stratify the overall HNSCC cohort by clinical and molecular markers, and therefore, try to predict treatment response, factors associated with the socioeconomic status were poorly explored $[15,16]$. Low socioeconomic status is traditionally attributed to reduced overall survival [17]. Interestingly, recent studies showed higher mortality rates in breast, prostate, and

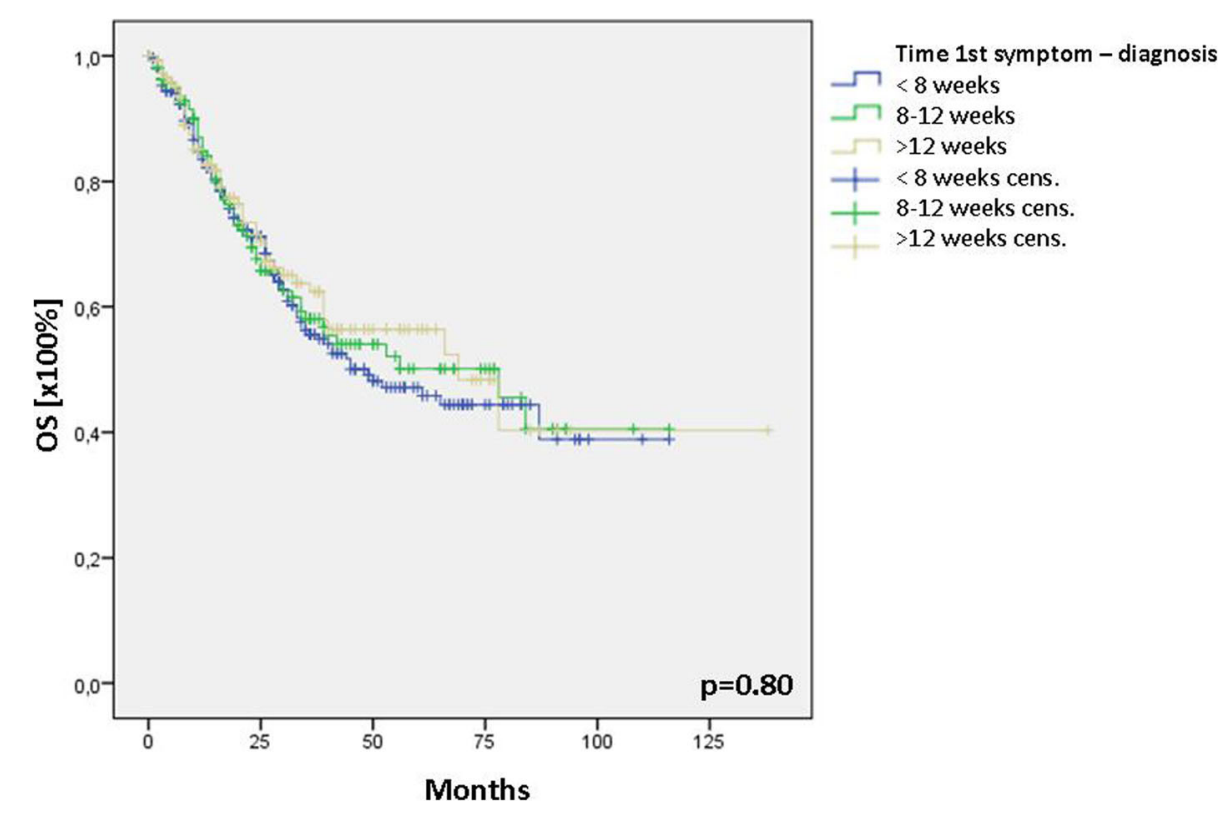

Fig. 1 Overall survival after stratification of the time frame first symptom - final therapy 

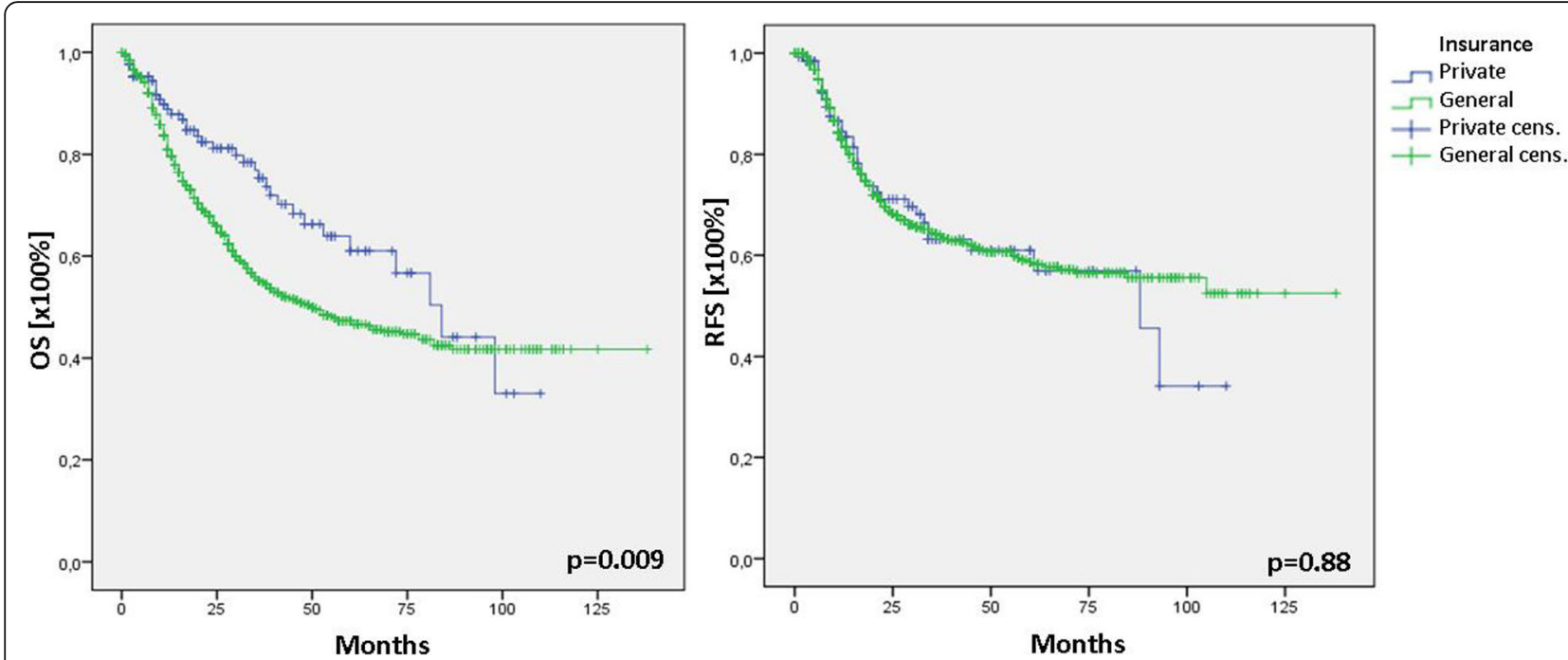

Fig. 2 Overall and recurrence-free survival after stratification of the insurance status

thyroid cancers as well as melanoma in a high-income cohort, hypothesising that too much medical care results in over-diagnosis and unnecessary treatment [18]. However, information on the impact of socioeconomic status in HNSCC is poor. There are broad inter-relations between the socioeconomic and the insurance status. Many studies investigated the insurance status as an independent risk factor in overall survival. Regarding different healthcare systems worldwide, results differ significantly. Particularly in countries without compulsory insurance, uninsured patients show significantly increased tumour stages at diagnosis and poor survival [2-6]. In Germany, there is a long tradition of compulsory insurance. However, there is an ongoing debate on whether access to the healthcare system is aggravated for patients with general insurance. This might be of major impact because the prolongation of treatment after tumour diagnosis was proven to reduce patients' survival $[9,19]$. While the prolongation of treatment caused by different insurance status can hardly be analysed, we focused on primary access (first perception of symptoms to diagnosis) to ENT-professionals, an aspect

Table 2 Forward-selected Cox-regression identified increased Tstatus (T3/4) and lymph node positivity $(\mathrm{N}+)$ being associated with a 2.2 and 1.9-fold risk of disease associated deaths, while symptom duration did not impact survival. Cl: confidence interval; HR: hazard ratio

\begin{tabular}{|c|c|c|c|}
\hline & $p$-value & HR & $95 \%-\mathrm{Cl}$ \\
\hline \multicolumn{4}{|l|}{ Symptom duration } \\
\hline$<8$ weeks vs. 8-12 weeks & 0.37 & 0.9 & $0.6-1.1$ \\
\hline $8-12$ weeks vs. $>12$ weeks & 0.59 & 1.1 & $0.8-1.6$ \\
\hline T1/2 vs. T3/4 & $<0.0001$ & 2.2 & $1.6-3.1$ \\
\hline No vs. N+ & $<0.0001$ & 1.9 & $1.3-2.2$ \\
\hline
\end{tabular}

that is often discussed as being prolonged in patients with general insurance. A total of 1,054 consecutively treated patients were included. Fourteen percent of the overall cohort had private insurance. The time interval between subjective symptom percipience and diagnosis was comparable in patients with general and private insurance, suggesting that there was no avoidable retardation of diagnosis generated by the health care system. Age and gender distribution as well as primary tumour location did not differ between the groups. However, patients with general insurance showed significantly advanced $\mathrm{T}$ status at the time of diagnosis. Underlying conditions resulting in different self-perception, as well as the attribution of early symptoms to severe illness, might be delusive at this point. In literature, a higher rate of patient's delay was demonstrated in heavy smokers and drinkers [10]. Also, education, income, and social support seem to play an important role [20]. Accordingly, patients with private insurance demonstrated significantly improved overall survival when compared with their counterparts with general insurance. Interestingly, we could not observe differences in the recurrence-free-survival, suggesting successful cancer treatment in both groups. There might be different explanations for these contradictory results including therapy associated deaths due to late toxicity and cancer independent comorbidity in patients with general insurance. An association between health behaviour (especially smoking/drinking), socioeconomic status that influence oncologic outcome irrespective of cancer stage, and therapeutic strategies have recently been demonstrated [21]. Also, after including risk factors like smoking, alcohol abuse, and nutritional status as co-factors, studies still showed a high relevance of the socioeconomic status as an independent risk factor. In a prospective longitudinal 
study, Choi et al. identified low income, as well as low education, as predictors for poor survival with an impressive aberration of survival rates [22, 23]. Concomitant depression represents another often underestimated, independent risk factor in the outcome of HNSCC that is strongly associated with socioeconomic factors. The prevalence of preoperative depressive symptoms in HNSC C patients is high. Rieke demonstrated that 19\% of patients with HNSCC suffer from pre- or post-therapeutic depression resulting in a $35 \%$ higher mortality [24]. Kim et al. showed a similar correlation between depression and mortality in patients with HNSCC; the incidence of depression was strongly associated with the pretreatment quality of life [25]. Also, the high influence of depression on post-treatment functional status and rehabilitation, as well as treatment adherence, has been shown in prospective studies $[17,26]$. Even if prospective data regarding the relevance of depression as an independent risk factor still has to be completed, the demonstrated literature shows the relevance of the allowance and treatment of such comorbidities. The treatment of depression not only improves the quality of life but dramatically contributes to therapy success. Hence, it should be part of every followup care in the treatment of HNSCC.

\section{Conclusions}

The time frame between the subjective perception of first symptoms and final therapy did not differ between patients with general and private insurances. However, patients with general insurance showed significantly advanced $\mathrm{T}$ status at the time of diagnosis when compared to those with private insurance. In Germany, access to otorhinolaryngological specialists is favourable in both patients with general and private insurance. Despite advanced $T$ status in patients with general insurance, the recurrence-free survival was comparable in both groups, indicating successful HNSCC treatment. However, overall survival was significantly better in patients with private insurance suggesting other socioeconomic factors influencing survival.

\section{Acknowledgements}

Not Applicable.

\section{Authors' contributions}

Concept (AK, HB), data acquisition (AK, HB, ST), formal analysis (AK, HB, ST), writing (AK, ST), editing (AK, HB, ST). All authors have read and approved the manuscript.

\section{Funding}

Open Access funding enabled and organized by Projekt DEAL.

\section{Availability of data and materials}

Data analysed from the daily ENT routine. The datasets generated and/or analysed during the current study are not publicly available because ethical approval does not include sharing raw data.

\section{Ethics approval and consent to participate}

The study was approved by the local Ethics Commission, Technical University Munich (No. 104/18S). A consent to participate is not applicable. Local tumor registry gave permission to use the given data.

No further administrative permissions were required to access and use the data/records described.

\section{Consent for publication}

Not applicable.

\section{Competing interests}

All authors declare no conflicts of interest that bias their work.

Received: 23 April 2020 Accepted: 20 December 2020

Published online: 08 January 2021

\section{References}

1. Gesellschaft RK.I.H.u.d. and d.e.K.i.D.e.V, Herausgeber, Krebs in Deutschland 2013-2014. 11: p. 24-26.

2. Panth $\mathrm{N}$, et al. Insurance status, stage of presentation, and survival among female patients with head and neck cancer. Laryngoscope. 2020;130(2):385-91.

3. Kwok J, et al. The impact of health insurance status on the survival of patients with head and neck cancer. Cancer. 2010;116(2):476-85.

4. Rohlfing $\mathrm{ML}$, et al. Insurance status as a predictor of mortality in patients undergoing head and neck cancer surgery. Laryngoscope. 2017;127(12): 2784-9.

5. Gupta A, et al. Impact of the insurance type of head and neck cancer patients on their hospitalization utilization patterns. Cancer. 2018;124(4): 760-8.

6. Takenaka $Y$, et al. Health insurance status and survival among patients with head and neck cancer in Japan. Int J Clin Oncol. 2016;21(3):517-22.

7. Montoro JR, et al. Prognostic factors in squamous cell carcinoma of the oral cavity. Braz J Otorhinolaryngol. 2008;74(6):861-6.

8. Massano J, et al. Oral squamous cell carcinoma: review of prognostic and predictive factors. Oral Surg Oral Med Oral Pathol Oral Radiol Endod. 2006; 102(1):67-76.

9. Murphy CT, et al. Survival Impact of Increasing Time to Treatment Initiation for Patients With Head and Neck Cancer in the United States. J Clin Oncol. 2016;34(2):169-78

10. Brouha X, et al. Role of alcohol and smoking in diagnostic delay of head and neck cancer patients. Acta Otolaryngol. 2005;125(5):552-6.

11. Dekate KN. Why head and neck squamous cell carcinoma diagnosed so late? Influence of health care disparities and socio-economic factor. Oral Oncol. 2014;50(11):e63.

12. Noonan B. Understanding the reasons why patients delay seeking treatment for oral cancer symptoms from a primary health care professional: an integrative literature review. Eur J Oncol Nurs. 2014;18(1): $118-24$.

13. Shafer WG. Initial mismanagement and delay in diagnosis of oral cancer. J Am Dent Assoc. 1975;90(6):1262-4.

14. Gomez I, et al. Is early diagnosis of oral cancer a feasible objective? Who is to blame for diagnostic delay? Oral Dis. 2010;16(4):333-42.

15. Knopf A, Fritsche MK, Li Y, CXCR4. A New Player in an Old Scene? ORL J Otorhinolaryngol Relat Spec. 2017;79(1-2):34-42.

16. Hoffmann TK, et al. Response Evaluation in Head and Neck Oncology: Definition and Prediction. ORL J Otorhinolaryngol Relat Spec. 2017;79(1-2): 14-23.

17. Singer $\mathrm{S}$, et al. Socio-economic disparities in long-term cancer survival-10 year follow-up with individual patient data. Support Care Cancer. 2017;25(5): 1391-9.

18. Welch HG, Fisher ES. Income and Cancer Overdiagnosis - When Too Much Care Is Harmful. N Engl J Med. 2017;376(23):2208-9.

19. Polesel J, et al. The impact of time to treatment initiation on survival from head and neck cancer in north-eastern Italy. Oral Oncol. 2017;67:175-82.

20. Inverso $G$, et al. Marital status and head and neck cancer outcomes. Cancer. 2015;121(8):1273-8.

21. Steenland K, Henley J, Thun M. All-cause and cause-specific death rates by educational status for two million people in two American Cancer Society cohorts, 1959-1996. Am J Epidemiol. 2002;156(1):11-21. 
22. Choi SH, et al. Socioeconomic and Other Demographic Disparities Predicting Survival among Head and Neck Cancer Patients. PLoS One. 2016; 11(3):e0149886.

23. Conway DI, et al. Estimating and explaining the effect of education and income on head and neck cancer risk: INHANCE consortium pooled analysis of 31 case-control studies from 27 countries. Int J Cancer. 2015;136(5):1125-39.

24. Rieke $\mathrm{K}$, et al. Depression and survival in head and neck cancer patients. Oral Oncol. 2017;65:76-82.

25. Kim SA, et al. Pretreatment depression as a prognostic indicator of survival and nutritional status in patients with head and neck cancer. Cancer. 2016; 122(1):131-40

26. Barber $\mathrm{B}$, et al. Depression as a predictor of postoperative functional performance status (PFPS) and treatment adherence in head and neck cancer patients: a prospective study. J Otolaryngol Head Neck Surg. 2015;44:38.

\section{Publisher's Note}

Springer Nature remains neutral with regard to jurisdictional claims in published maps and institutional affiliations.

Ready to submit your research? Choose BMC and benefit from:

- fast, convenient online submission

- thorough peer review by experienced researchers in your field

- rapid publication on acceptance

- support for research data, including large and complex data types

- gold Open Access which fosters wider collaboration and increased citations

- maximum visibility for your research: over $100 \mathrm{M}$ website views per year

At $\mathrm{BMC}$, research is always in progress.

Learn more biomedcentral.com/submissions 